\section{Efficacy of Etanercept in Lymphedema Associated with Psoriatic Arthritis}

\section{To the Editor:}

Lymphedema is a rare complication of psoriatic arthritis (PsA) whose management is not standardized. We report the prompt resolution of left upper limb lymphedema in a patient with PsA treated with etanercept.

A 43-year-old man presented to our department in June 2003 with oligoarthritis affecting the hands, wrists, and elbows. He had been diagnosed 9 years earlier with PsA based on a combination of asymmetric oligoarthritis, dactylitis affecting all digits of the right hand, swan-neck deformity of the fifth fingers of both hands, psoriasis at the navel and nails, and negative tests for rheumatoid factor and anti-cyclic citrullinated peptide (anti-CCP) antibodies. His left forearm was swollen following diagnosis of its rheumatic disease (Figure 1A). The axillary nodes were not enlarged. An erythematous plaque developed a few months later over the swollen forearm. Laboratory evaluation revealed elevated acute-phase reactants [C-reactive protein, $27 \mathrm{mg} / \mathrm{l}($ normal $<5)$; erythrocyte sedimentation rate, $62 \mathrm{~mm} / \mathrm{h}($ normal <20)]. He was negative for the HLA-B27 antigen. Serological tests for filarial infections were negative. A skin biopsy showed psoriasiform epidermal hyperplasia with marked dermal edema and no evidence of infection. Bilateral sacroiliitis grade 3 was seen on radiographs of the pelvis. Radiographs of the left forearm, elbow, and wrist were normal. Magnetic resonance imaging of the left forearm showed swelling of the subcutaneous fat with normal signal from soft tissues, muscle, and bone. The final diagnosis was left upper limb lymphedema stage II (International Society of Lymphology).

Sulfasalazine (SSZ; $2 \mathrm{~g} /$ day) prescribed for 7 months and then methotrexate (MTX, up to $20 \mathrm{mg} / \mathrm{wk}$ ) prescribed during 33 months, both combined with nonsteroidal antiinflammatory drugs (rofecoxib $25 \mathrm{mg}$ /day or flurbiprofen $200 \mathrm{mg} /$ day), failed to adequately control the disease. The oligoarthritis recurred and the lymphedema remained unchanged. Etanercept was administrated subcutaneously $50 \mathrm{mg}$ once a week, initially in combination with MTX $7.5 \mathrm{mg} /$ week. After 8 weeks of treatment, arthritis and laboratory test abnormalities resolved completely. Further, the fore- arm swelling decreased markedly (Figure 1B). In 2008, after 34 months of treatment, the difference in forearm circumference between the 2 sides at the olecranon was only $0.5 \mathrm{~cm}$.

Lymphedema is a rare manifestation of $\mathrm{PsA}^{1,2}$. The upper limbs are the most common sites of involvement, with the right side being preferentially affected ${ }^{1}$. It could be difficult to link lymphedema to the rheumatic condition. Other causes of upper limb edema such as thrombophlebitis, allergic reaction, septic cellulitis, panniculitis, or edema due to filarial infections should be excluded. The pathogenesis of lymphedema associated with PsA is unclear. Arthritis or tenosynovitis alone does not impair lymphatic drainage $^{2}$. Lymphedema may be chiefly related to lymphatic function abnormalities, which can be documented by lymphoscintigraphy ${ }^{2-5}$.

The management of lymphedema in patients with chronic inflammatory joint diseases such as PsA is a challenge. Treatments with various degrees of success include corticosteroids injected intravenously ${ }^{4}$ or intraarticularly ${ }^{3}, \quad$ D-penicillamine ${ }^{5}$, chloroquine ${ }^{5}, \mathrm{SSZ}^{1,6}, \mathrm{MTX}^{7}$, cyclosporine $^{1}$, and physical therapy $y^{1,5}$. In our patient, the recombinant human soluble receptor for tumor necrosis factor- $\alpha$ (TNF- $\alpha$ ), etanercept, was effective, whereas SSZ and MTX were not. Successful treatment with etanercept of lymphedema has been reported in another patient with PsA ${ }^{4}$. TNF- $\alpha$ antagonists have also been found effective in the treatment of lymphedema associated with other chronic inflammatory diseases including rheumatoid arthritis (etanercept) ${ }^{7}$, ankylosing spondylitis (infliximab) ${ }^{6}$, and Crohn's disease (infliximab) ${ }^{8}$. The small number of published cases precludes an evaluation of specific effects of each TNF- $\alpha$ antagonist.

TNF- $\alpha$ is among the cytokines involved in the pathogenesis of PsA as part of a cascade of proinflammatory molecules that also includes interleukin 8 (IL-8), IL-17, IL-23, and interferon type $1^{9}$. In a study of TNF- $\alpha$ transgenic mice, TNF- $\alpha$ stimulated osteoclast precursors to produce the vascular endothelial growth factor-C (VEGF-C, a lymphatic growth factor) via the nuclear factor- $\kappa \mathrm{B}(\mathrm{NF}-\kappa \mathrm{B})$ pathway ${ }^{10}$. The increase in VEGF-C production led to a significant increase in lymphangiogenesis, an abnormality also seen in the joints of mice with serum-induced arthritis ${ }^{10}$. TNF$\alpha$ antagonist therapy significantly decreased the joint inflammation in our case, but unfortunately failed to diminish the lymphatic vasculature ${ }^{10}$.
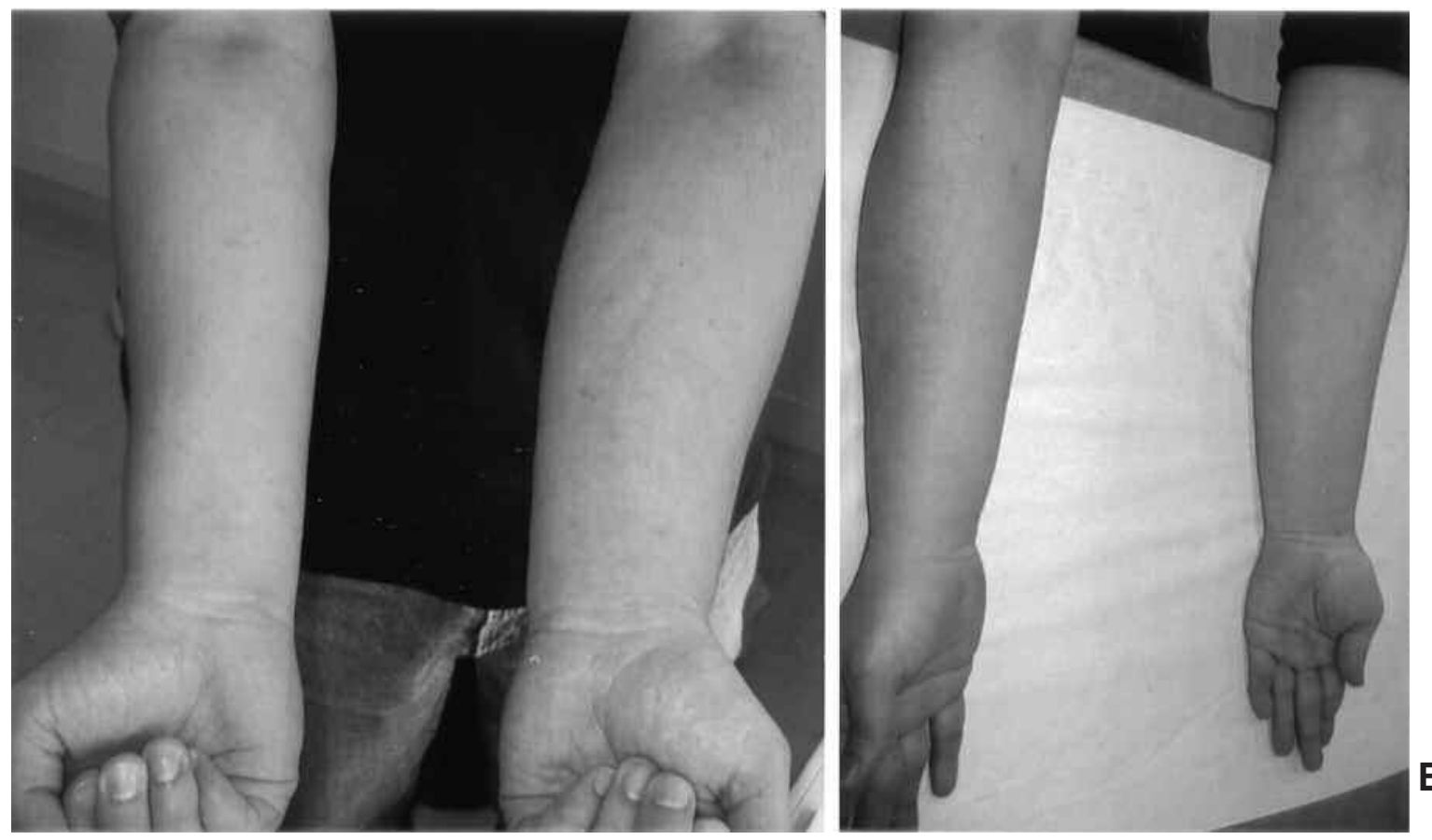

B

Figure 1. A. Left side: Enlargement of the upper left forearm, indicating lymphedema. B. Right side: Resolution of the lymphedema following anti-TNF- $\alpha$ therapy. 
TNF- $\alpha$ antagonists hold promise for the treatment of lymphedema associated with chronic inflammatory joint disease.

FERNANDO KEMTA LEKPA, MD; ANDRA ECONOMU-DUBOSC, MD; CLAIRE FEVRE, MD; PASCAL CLAUDEPIERRE, MD; XAVIER CHEVALIER, PhD, MD, Service de Rhumatologie, Hôpital Henri Mondor, 51 Avenue du Maréchal de Lattre de Tassigny, 94100, Créteil, France. Address reprint requests to Prof. Chevalier.

E-mail: xavier.chevalier@hmn.aphp.fr

\section{REFERENCES}

1. Böhm M, Riemann B, Luger TA, Bonsmann G. Bilateral upper limb lymphoedema associated with psoriatic arthritis: a case report and review of the literature. Br J Dermatol 2000;143:1297-301.

2. Kiely PD, Bland JM, Joseph AE, Mortimer PS, Bourke BE. Upper limb lymphatic function in inflammatory arthritis. J Rheumatol 1995;22:214-7.

3. Salvarani C, Cantini F, Olivieri I, et al. Distal extremity swelling with pitting edema in psoriatic arthritis: evidence of 2 pathological mechanisms. J Rheumatol 1999;26:1831-4.

4. Doffoël-Hantz V, Sparsa A, Verbeke S, Tricard MJ, Bonnetblanc
JM, Bédane C. Lymphoedema: a rare complication of inflammatory rheumatism. Successful treatment with etanercept. Eur J Dermatol 2007;4:337-8.

5. Mulherin DM, FitzGerald O, Bresnihan B. Lymphoedema of the upper limb in patients with psoriatic arthritis. Semin Arthritis Rheum 1993;22:350-6.

6. Almodóvar R, Zarco P, Quirós FJ, Mazzucchelli R. Infliximab treatment efficacy in lymphoedema associated with ankylosing spondylitis. Rheumatology Oxford 2004;43:1456.

7. Ostrov BE. Beneficial effect of etanercept on rheumatoid lymphedema. Arthritis Rheum 2001;44:240-1.

8. Kugathasan S, Miranda A, Nocton J, Drolet BA, Raasch C, Binion DG. Dermatologic manifestations of Crohn disease in children: response to infliximab. J Pediatr Gastroenterol Nutr 2003;37:150-4.

9. Ciocon DH, Kimball AB. Psoriasis and psoriatic arthritis: separate or one and the same. Br J Dermatol 2007;157:850-60.

10. Zhang Q, Lu Y, Proulx ST, et al. Increased lymphangiogenesis in joints of mice with inflammatory arthritis. Arthritis Res Ther 2007;9:R118 (doi 10.1186/ar2326).

J Rheumatol 2009;36:1; doi:10.3899/jrheum.080453 